\title{
Reporting on Adverse Drug Reactions: Knowledge, Attitudes and Practice Among Physicians Working at Healthcare Institutions in Al-Buraimi Governorate-Oman
}

\author{
Talib Salim Al Kalbani ${ }^{1}$, Hilal Salim Al Shamsi ${ }^{2}$ \& Abdullah Ghthaith Almutairi ${ }^{3}$ \\ ${ }^{1}$ Directorate of Pharmacy and Medical Stores, Directorate General of Health Services, Al-Buraimi Governorate, \\ Ministry of Health, Oman \\ ${ }^{2}$ Directorate of Planning and Studies, Directorate General of Health Services, Al-Buraimi Governorate, Ministry \\ of Health, Oman \\ ${ }^{3}$ Quality and Patients Safety Department, Prince Nasser bin Saad Hospital, Al-Ghat Province, Ministry of Health, \\ Saudi Arabia \\ Correspondence: Hilal Salim Al Shamsi, Directorate of Planning and studies, Directorate General of Health \\ Services, Al-Buraimi Governorate, Ministry of Health, Oman.
}

Received: June 13, 2018 Accepted: July 16, 2018 Online Published: July 25, 2018

doi:10.5539/gjhs.v10n8p107

URL: https://doi.org/10.5539/gjhs.v10n8p107

\begin{abstract}
Objective: The study aims to evaluate postgraduate resident physicians' knowledge, attitudes and practices related to reporting adverse drug reactions (ADRs). It also aims to investigate the causes of poor ADR reporting and to suggest possible ways to improve the reporting methods.

Methods: A cross-sectional study was conducted using a self-administered questionnaire. The questionnaire sought to obtain the physicians' demographic characteristics, knowledge and practices in relation to ADRs and to identify the factors that affect and encourage ADR reporting. The questionnaire was distributed to physicians $(\mathrm{n}=117)$ working at governmental healthcare institutions in Al-Buraimi governorate in Oman.
\end{abstract}

Results: The response rate was $80 \%$. Median score for the knowledge components of ADR reporting was 5 (total score: 7); it was 5 (total score: 5) for the attitude components. No significant difference for the knowledge and attitude scores was found between gender, age group or physicians' medical speciality. Eighty-four of the physicians (89.4\%) knew about pharmacovigilance and serious ADRs. Eighty-eight of the physicians (93.6\%) believed that reporting ADRs should be mandatory. No statistical differences were found between general practitioners and specialists who felt that ADR reporting should be either compulsory or voluntary $(p=0.080)$. Seventy-eight of the physicians (83\%) noted that the lack of awareness about the reporting procedures is the main reason for not reporting ADRs. In this regard, there were no statistically significant differences between physicians younger than 45 or older than $45(p=0.835)$.

Conclusion: Deficits in the practice of ADR reporting can be resolved in the future only if all physicians in the healthcare profession are aware of the importance of reporting ADRs, the reporting system and their obligation to report ADRs.

Keywords: knowledge, perception, physicians, students, adverse drug reactions reporting, Pharmacovigilance

\section{Introduction}

Safety and efficacy are the two major concerns about a drug. While the efficacy of a drug can be quantified with relative ease, the same cannot be said about its safety. This is because the adverse effect of a drug may be uncommon (but very serious), and many patients may be affected by or subjected to a potential risk before the relationship the efficacy and safety of the drug is established.

Unfortunately, adverse drug reactions (ADRs) are one of the major causes of mortality and morbidity, worldwide (Lazarou, Pomeranz, \& Corey, 1998). According to the World Health Organization (WHO), an ADR is any noxious, unintended and undesired effect of a drug that occurs at doses used in humans for prophylaxis, diagnosis or cure of a disease (World Health Organization, 2002). In addition to the human costs, ADRs have a major impact on public health by imposing a considerable economic burden on society and the already-stretched healthcare 
systems (Ayani et al., 1999; Wu \& Pantaleo, 2003).

In contrast, spontaneous ADR reporting has contributed significantly to successful pharmacovigilance. In this regard, healthcare professionals have made significant contributions to ADR databases and this has encouraged ongoing ascertainment of the benefit-risk ratio of some drugs (Ahmad, 2003; Ralph Edwards \& Olsson, 2002); it has also contributed to signal detection of unsuspected and unusual ADRs previously undetected during the initial evaluation of a drug (Lexchin, 2006; Wysowski \& Swartz, 2005). In spite of these benefits, underreporting remains a major drawback of spontaneous reporting (Feely, Moriarty, \& O'Connor, 1990; Smith et al., 1996). It is estimated that only $6-10 \%$ of all ADRs are reported (Feely et al., 1990; Figueiras, Tato, Fontaiñas, \& Gestal-Otero, 1999).

Studies conducted in different settings indicate that healthcare professionals have inadequate knowledge about pharmacovigilance and there is a high degree of underreporting. Pharmacovigilance is still in its infancy in India, and there is very limited knowledge about this discipline. However, the Indian National Pharmacovigilance Programme lacks continuity due to lack of awareness and inadequate training about drug safety monitoring among healthcare professionals in India (Rajesh, Vidyasagar, \& Nandakumar, 2011). Assessment of healthcare professionals' awareness of pharmacovigilance is very important due to underreporting of ADRs.

In order to improve the ADR reporting rate, it is important to improve healthcare professionals' knowledge, attitude and practices (KAP) regarding ADR reporting and pharmacovigilance. Most likely, the best time to achieve this goal is during the undergraduate and postgraduate medical education of doctors. This study is a step in that direction. It endeavours to evaluate the baseline KAP related to ADR monitoring and pharmacovigilance of the postgraduate resident doctors at two teaching hospitals in Maharashtra. This would help in planning interventions amongst this group of doctors.

Core factors, such as KAP can help in understanding the relationship between a physician and patients and other healthcare professionals and formulating strategies to encourage physicians to report ADRs. Although various studies on ADR reporting among healthcare professionals have been conducted in different parts of world to improve the safe use of medications, there has been no empirical research from the Al-Buraimi region of Oman regarding physicians' attitudes toward ADR reporting. Therefore, this study is a modest endeavor to evaluate the knowledge that postgraduate resident physicians working in Al-Buraimi Governorate healthcare institutions have about ADR reporting.

\section{Methods}

\subsection{Study Design}

This cross-sectional study used a questionnaire to obtain data. The study was conducted among postgraduate resident physicians working in Al-Buraimi Governorate healthcare institutions, in Oman to assess their knowledge about ADR reporting.

\subsection{Study Population}

After calculation, the sample size was found $(\mathrm{n}=117)$ physicians. Hence, proportional stratified random sampling was used to draw a sample on the basis of institution level (77 physicians from Al-Buraimi Referral Hospital, 23 physicians from Al-Buraimi Extended Health Centre and 16 physicians from health centres); the size of the sample in each stratum is taken in proportion to the size of the stratum. Physicians who had been affiliated with the Ministry of Health (MOH) for less than one year and/or who were on leave were excluded from the study.

\subsection{Data Collection Measurements and Tools}

The questionnaire was prepared using existing information from the literature about healthcare professionals' KAP in relation to ADRs. The questionnaire was subjected to test/re-test reliability and alternate form reliability. The internal reliability (consistency) of the items in the questionnaire was determined by computing Cronbach's alpha.

The KAP questionnaire was divided into four parts. The first part consisted of questions related to the respondents' demographic characteristics. The second part contained questions about the respondents' knowledge of and experience with ADRs. The third part contained questions related to the barriers to reporting ADRs. The final part included questions about the factors that encourage physicians to report ADRs. Knowledge and attitude were calculated by assessing the responses to specific questions. In the knowledge section, a score of 1 was given for each correct answer. The maximum score was 7 and the minimum score was 0 . In the attitude section, the answers to the questions ranged from sure to not sure. The total possible score for the attitude components was 5 . The mean or median score was calculated. Approval from the research committee was obtained.

After obtaining informed consent, the questionnaire was distributed through the nurse in-charge at the health centres, and in each clinic in the case of the Extended Health Centre and Al-Buraimi Referral Hospital. To 
maximize the response rate, they handed the questionnaire to the physicians after explaining the purpose of the study, and they requested that the physicians return the completed survey immediately. To increase the clarity of the questionnaire, an explanatory letter was attached to it. The physicians that were busy when they were given the questionnaire were asked to complete the survey within 1 day and return it to the nurse in-charge (who was informed about the nature of the study). The physicians that did not respond by the next day were called and the questionnaire was re-administered if the reason for their non-response was loss of the questionnaire. If the reason for their non-response was their busy schedule, the physicians were asked to suggest a suitable time when they would want to be contacted to return the completed questionnaire. The completed questionnaires were collected anonymously.

The data were entered into a computer using Statistical Package for the Social Science (SPSS) version 21. Frequencies were computed for all of the variables. After testing the normality of distribution and skewness, the Mann-Whitney U test or Kruskal-Wallis test was used to compare the median scores for the knowledge and attitude components among the different demographic variables, such as gender, age group variations and educational qualifications. Spearman's correlation was used to determine if there was any relationship between knowledge and attitude. Differences between the age groups were analyzed using Pearson's chi-squared tests. For all the tests, a p level less than or equal to 0.05 was considered to be statistically significant.

\section{Results}

Out of the 117 administered questionnaires, 94 were returned, resulting in a response rate of $80 \%$. The majority of respondents $62(66 \%)$ were males; 32 (34\%) were females. With regards to age, $80(85.1 \%)$ respondents were 45 or younger and $14(14.9 \%)$ were older than 45 . Considering the number of years of experience, the vast majority of the respondents had more than 5 years of experience $(83 \%)$. Sixteen $(17 \%)$ of the physicians were Omani and 78 (83\%) were non-Omani. Table 1 shows the demographic characteristics of the respondents.

Table 1. Demographic Characteristics of the physicians participating in the study ( $\mathrm{n}=94)$

\begin{tabular}{lcc}
\hline Characteristics & Frequency(n=94) & Percentage (\%) \\
\hline Sex & 62 & 66 \\
Male & 32 & 34 \\
Female & & \\
\hline Age group & 80 & 85.1 \\
$<=\mathbf{4 5}$ & 14 & 14.9 \\
$>\mathbf{4 5}$ & & \\
\hline Designation & 46 & 48.9 \\
General Practitioner & 48 & 51.1 \\
Specialist & & 55.3 \\
\hline Current Working Place & 52 & 34 \\
Secondary Hospital & 32 & 10.6 \\
Extended Health centre & 10 & 17 \\
Health-centre & & 83 \\
\hline Total clinical experience(years) & 16 & 17 \\
$<=5$ & 78 & 83 \\
$>\mathbf{5}$ & &
\end{tabular}

The physicians' knowledge of and attitude about reporting ADRs were quantified by assessing their responses to specific questions. In terms of knowledge, a score of 1 was assigned to the correct responses to the questions, and 
the total possible score was 7 . Using this scoring system, it was observed that the overall median score was 5 , and the scores ranged from 2 to 6 . The correct definition of side effect was identified by 78 (83\%) of the respondents. Eighty-four (89.4\%) of the respondents knew the definitions of pharmacovigilance and serious ADRs. Only 42 (44.7\%) of the respondents knew the location of the WHO collaborating centre for international drug monitoring (Table 2). The respondents' answers to the questions assessing their attitude about ADR reporting ranged from sure to not sure; the maximum possible score was 5 . The median score was $5 ; 78(83 \%)$ of the respondents stated that ADR reporting is a professional obligation. Ninety-two (97.9\%) respondents thought that the ADR reporting and monitoring system improves patient care (Table 3 ). The median scores for knowledge and attitude in relation to the demographic variables are shown in Table 2 . As seen, physicians that were 45 or younger had slightly higher knowledge scores than those that were older than 45 ; however, the differences were not statistically significant. Similarly, the physicians that had more than 5 years of experience had higher median scores than the physicians with 5 years' of experience or less. This result implies that clinical experience did improve their knowledge of and attitude about reporting ADRs.

The co-efficient for knowledge and attitude was generated using Spearman's correlation; it was found to be 0.532 , which suggests a positive correlation. As the physician's knowledge of ADRs increased, their attitudes increased.

Table 2. Relationship between demographic Characteristics and knowledge, attitude scores

\begin{tabular}{|c|c|c|c|c|}
\hline Characteristics & $\begin{array}{c}\text { Knowledge } \\
\text { (median) }\end{array}$ & P Value* & $\begin{array}{l}\text { Attitude } \\
\text { (median) }\end{array}$ & $P$ value* \\
\hline \multicolumn{5}{|l|}{ Sex } \\
\hline Male & 5 & \multirow{2}{*}{0.260} & 5 & \multirow{2}{*}{0.128} \\
\hline Female & 5 & & 5 & \\
\hline \multicolumn{5}{|l|}{ Age group } \\
\hline$<=45$ & 5 & \multirow{2}{*}{0.255} & 5 & \multirow{2}{*}{0.727} \\
\hline$>45$ & 4 & & 5 & \\
\hline \multicolumn{5}{|l|}{ Designation } \\
\hline General Practitioner & 5 & \multirow{2}{*}{0.965} & 5 & \multirow{2}{*}{0.709} \\
\hline Specialist & 5 & & 5 & \\
\hline \multicolumn{5}{|l|}{ Current Working Place** } \\
\hline Secondary Hospital & 5 & \multirow{3}{*}{.599} & 5 & \multirow{3}{*}{.733} \\
\hline Extended Health centre & 4 & & 5 & \\
\hline Health-centre & 5 & & 5 & \\
\hline \multicolumn{5}{|c|}{ Total clinical experience(years) } \\
\hline$<=5$ & 4 & \multirow{2}{*}{0.225} & 5 & \multirow{2}{*}{0.974} \\
\hline$>5$ & 5 & & 5 & \\
\hline
\end{tabular}

* $p$ value generated using Mann-Whitney U tests Pearson's and Fisher's exact tests;

** $p$ value generated using Kruskal-Wallis Test

The components related to practices are shown in Table 3. A total of 34 (36.1\%) physicians stated that they have reported ADRs. Eighty-eight physicians (93.6\%) mentioned that reporting ADRs should be mandatory; no statistically significant differences were found between general practitioners and specialists $(\mathrm{P}>0.05)$. 
Table 3. Practice of Adverse drug reactions reporting

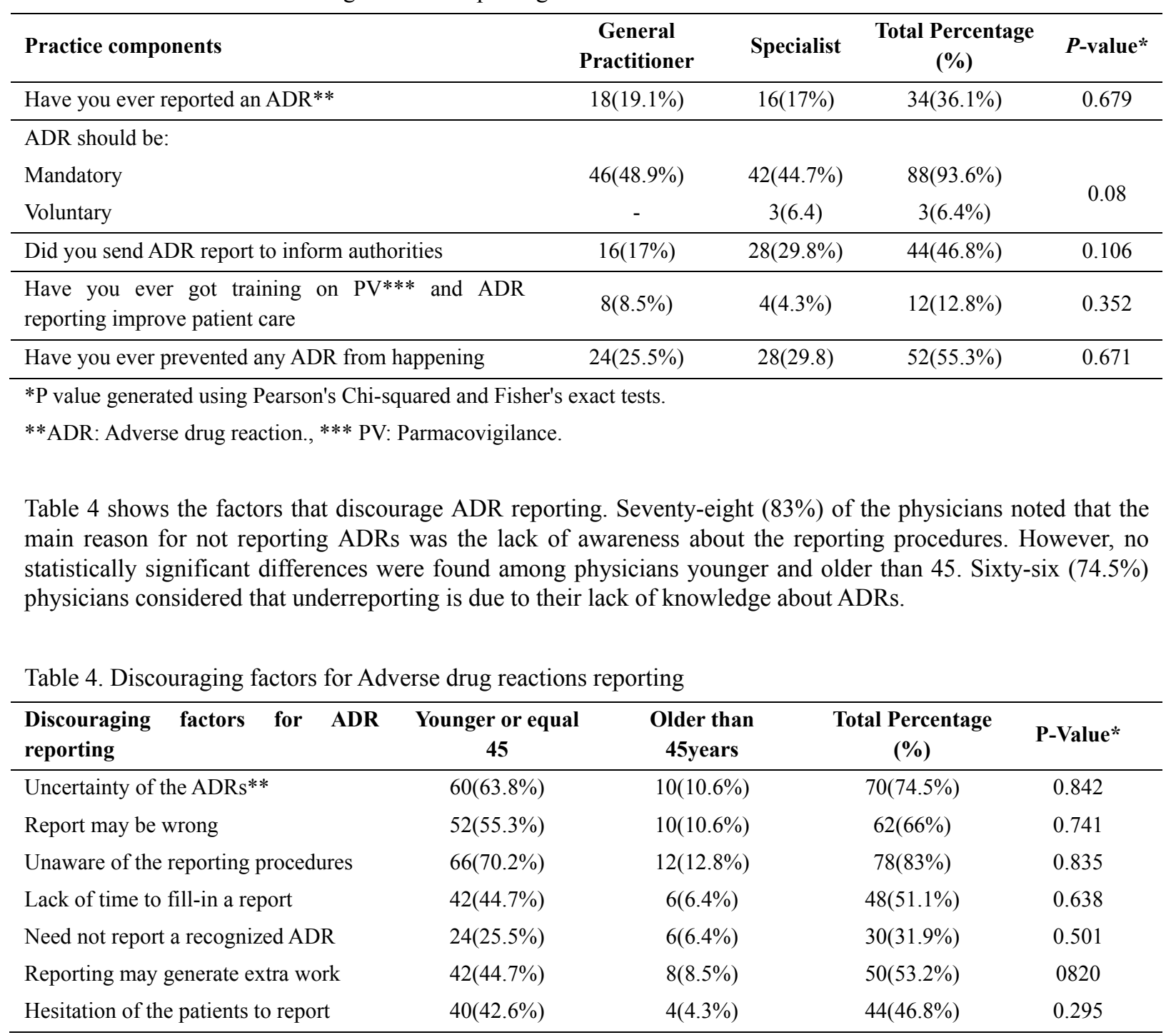

*P value generated using Pearson's Chi-squared and Fisher's exact tests.

ADRs:Adverse drug reactions

Table 5. Suggested Methods of improving Adverse drug reactions reporting

\begin{tabular}{lcccc}
\hline $\begin{array}{l}\text { Suggested Methods of improving ADR } \\
\text { reporting }\end{array}$ & $\begin{array}{c}\text { Younger or equal } \\
\mathbf{4 5}\end{array}$ & $\begin{array}{c}\text { Older than } \\
\mathbf{4 5 y e a r s}\end{array}$ & $\begin{array}{c}\text { Total Percentage } \\
\text { (\%) }\end{array}$ & P-Value* \\
\hline ADRs** information sheet at pharmacy & $64(68.1 \%)$ & $6(6.4 \%)$ & $70(74.5 \%)$ & 0.038 \\
DIC*** assistance & $70(74.5 \%)$ & $6(6.4 \%)$ & $76(80.9 \%)$ & 0.006 \\
Continuous education and workshops & $76(80.9 \%)$ & $12(12.8 \%)$ & $88(93.6 \%)$ & 0.354 \\
Encouraging patients to report & $76(80.9 \%)$ & $14(14.9 \%)$ & $90(95.7 \%)$ & 0.545 \\
Encouraging all healthcare professional to & $78(83 \%)$ & $14(14.9 \%)$ & $92(97.9 \%)$ & 0.672 \\
report & $74(78.7 \%)$ & $8(8.5 \%)$ & $82(87.2 \%)$ & 0.01 \\
Easy accessibility to ADRs forms & $76(80.9 \%)$ & $10(10.6 \%)$ & $86(91.5 \%)$ & 0.039 \\
Training to report an ADRS & &
\end{tabular}

*P value generated using Pearson's Chi-squared and Fisher's exact tests.

**ADRs: Adverse drug reactions.

***DIC: Drug Information Centre. 
The suggested methods for improving ADR reporting are shown in Table 5. Encouraging all healthcare professionals and patients to report ADRs and providing healthcare professionals with continuous education and workshops were the methods most often suggested $(97.9 \%, 95.7 \%$ and $93.6 \%$, respectively). No statistically significant differences were found among the physicians younger and older than $45(P>0.05)$.

\section{Discussion}

The response rate for completing the questionnaire was $80 \%$; that result was approximately equal to the response rate of studies carried out in India (Desai, Iyer, Panchal, Shah, \& Dikshit, 2011), Germany (Hasford, Goettler, Munter, \& Müller-Oerlinghausen, 2002), northern Italy (Cosentino, Leoni, Banfi, Lecchini, \& Frigo, 1997) and the United Kingdom (UK) (Eland et al., 1999), and similar to the response rate of studies in Nigeria (Oshikoya \& Awobusuyi, 2009), the UK (Belton, Lewis, Payne, Rawlins, \& Wood, 1995) and Scotland (Bateman, Sanders, \& Rawlins, 1992).

A spontaneous and voluntary reporting system is an integral component of a pharmacovigilance programme (Vallano et al., 2005; Waller, 2006). Despite global census for this type of reporting system, underreporting of ADRs is still a worldwide phenomenon, as established in previous studies (Aagaard, Nielsen, \& Hansen, 2009; Belton et al., 1995; Murphy \& Frigo, 1993; Rishi, Patel, \& Bhandari, 2012). The present study included all physicians working at governmental primary and secondary healthcare institutions in Al-Buraimi Governorate in Oman.

The current study has shown that physicians have adequate knowledge about ADRs and ADR reporting. In our study, about $78(83 \%)$ and $84(89.4 \%)$ of the physicians stated the correct definition of side effects and pharmacovigilance, respectively. That result is higher than the previous reports among resident doctors in many countries across Europe (Herdeiro, Figueiras, Polónia, \& Gestal-Otero, 2005; Milstien et al., 1986; Pougetzago, Lapeyremestre, Bagheri, \& Montastruc, 1995), America (Milstien et al., 1986; Rogers et al., 1988) and Asia (Li et al., 2004; Oshikoya \& Awobusuyi, 2009; Rehan, Vasudev, \& Tripathi, 2002).

In our study, 64 (68.1\%) of the respondents thought that ADRs should be reported only if the reaction was serious; this is similar to the finding reported in one study (Gupta \& Udupa, 2011). Hence, physicians' awareness about the need for reporting all ADRs should be improved in healthcare institutions in Al-Buraimi Governorate in Oman.

Ninety-two (97.9\%) physicians felt that an ADR reporting and monitoring system improves patient care, and 78 (83\%) physicians felt that reporting ADRs is a professional obligation. These results were higher than the findings reported in previous studies conducted in India (Bateman et al., 1992) and the UK (Ramesh, Pandit, \& Parthasarathi, 2003).

However, this study found that the practice of ADR reporting in this population of physicians was poor (36.1\%). Similarly, Indian studies conducted at Mumbai (Muraraiah, Rajarathna, Divyasree, Basavalingu, \& Jayanthi, 2011), Mysore (Goldman, 1998) and Muzzafarnagar (Tabali et al., 2009) found that the actual practice of ADR reporting was lacking.

In Oman, ADR reporting is a voluntary activity. Surprisingly, in our study, 88 (93.6\%) of the physicians stated that ADR reporting should be mandatory. Mandatory reporting of ADRs will not only enhance the quality of the reports, it will also be useful in developing a culture of reporting among physicians (Goldman, 1998).

Our findings are similar to the results reported by Tabali et al. (2009), which demonstrated that educational intervention can increase physicians' awareness of ADRs and that physicians can incorporate the knowledge they gain from face-to-face training into their everyday clinical practice. However, the effects of the educational intervention were temporary; hence, regular retraining is essential. One of the better means of overcoming underreporting is to increase the healthcare professionals' KAP about ADR monitoring and pharmacovigilance programmes (Palaian, Ibrahim, \& Mishra, 2011). Educational intervention has been shown to improve ADR reporting in Portugal (Scott et al., 1990) and in Rhode Island in the United States (US) (Blenkinsopp, Wilkie, Wang, \& Routledge, 2007).

Promoting patient self-reporting was the second method that physicians suggested for improving ADR reporting. The benefits of this idea have been confirmed in different studies (Blenkinsopp et al., 2007; Van Hunsel, Passier, \& Van Grootheest, 2009). Patient self-reporting plays a complimentary role in increasing the level of ADR reporting. Moreover, efforts should also be made to ensure that the patients' self-reporting process is simple and straightforward.

Patient self-reporting is effective because: 1) consumers become active players in drug safety with respect to pharmacovigilance, and they can actively contribute through an integrated and efficient reporting system; 2) it 
enables ADRs to be detected earlier and it helps ensure that more ADRs will be reported, thereby helping overcome the underreporting problems of the current system; and 3) it will promote consumer rights (A., Izham, M., \& P., 2010).

A review on ADR reporting by patients indicated that this activity has more potential benefits than drawbacks. ADRs that were not previously reported by healthcare professionals were identified by direct patient ADR reports (Blenkinsopp et al., 2007). It was also found that there is a need to develop a proactive pharmacovigilance structure in India for direct patient reporting of ADRs (Rishi et al., 2012).

Easy accessibility to ADRs is one of the methods suggested by physicians to encourage ADR reporting. Currently, online reporting has replaced the traditional forms used to report ADRs; and this could be considered to be the main method for improving reporting. Online reporting has been found to improve ADR reporting by most physicians in Romania (Paveliu, Bengea-Luculescu, Toma, \& Paveliu, 2013).

The factors dissuading resident doctors from spontaneously reporting ADRs were primarily related to their lack of understanding of the reporting procedure $(83 \%)$. These misperceptions about the procedure led to the physicians being apprehensive that completing a report would increase their workload $(41.1 \%)$ or they might be wrong in their identification of ADRs (66\%). In addition, some of the physicians felt uncertain about ADRs; they found it difficult to decide whether or not an ADR has occurred (74.5\%). These factors have also been pointed out in a study conducted in India (Rishi et al., 2012). These observations were consistent with earlier reports (Fadare, Enwere, Afolabi, Chedi, \& Musa, 2011; Khalili, Mohebbi, Hendoiee, Keshtkar, \& Dashti-Khavidaki, 2012; Rishi et al., 2012). In other European countries, the main cause of underreporting was attributed to lack of time and work overload (Herdeiro et al., 2005). Our study results indicate that lack of time was only the fourth reason for underreporting (51.1\%).

This study has some limitations. The data were only obtained from some government healthcare institutions in Oman. However, the study findings can be generalized if they are further extended to the private sector in this country. The inherent limitations of questionnaire-based studies, such as subjective responses and recall bias, must also be noted. It would have been more scientific to use a qualitative research methodology (in-depth interviews, focus group discussions) for this study. A qualitative research approach may be useful for gaining a better understanding of the knowledge, opinions and attitudes of the doctors and it may also help identify the elements that might be improved in the ADR reporting system to support spontaneous notification. Although the study's response rate was fairly good $(80 \%)$, a higher response rate would have made it possible to draw more certain conclusions.

\section{Conclusion}

The physicians working in the governmental healthcare institutions in Oman have a fairly good level of knowledge of and attitude about ADR reporting, but limited practice in reporting ADRs and pharmacovigilance. The deficits in the practice of ADR reporting can be resolved only if the prescribing physicians are aware of the importance of reporting, the reporting system and their obligation to report ADRs. Finally, a KAP study has some limitations (Launiala, 2009), and it would be inappropriate to plan interventions based on the findings of this study alone. However, this study does provide insights into the possible interventions that could be planned in the future. This study has just scratched the surface of this important issue by identifying the KAP of ADR reporting among prescribing physicians in Oman and the reasons for their underreporting of ADRs.

\section{Competing Interests Statement}

The authors declare that there are no competing or potential conflicts of interest.

\section{References}

A., A., Izham, M., M., I., \& P., S. (2010). Importance of consumer pharmacovigilance system in developing countries: a case of Malaysia. Retrieved from https://www.researchgate.net/profile/Mohammed Alshakka/publication/220021039_Alshakka_MA_Mohamed_Izham_MI_Subish_P_Importance_of_consum er_pharmacovigilance_system_in_developing_countries_a_case_of_Malaysia/links $/ 00 \mathrm{~b} 7 \mathrm{~d} 52 \mathrm{f} 33 \overline{5} \mathrm{~b} \mathrm{f} 7 \mathrm{f} 9 \mathrm{~b} 700$ 0000.pdf

Aagaard, L., Nielsen, L. H., \& Hansen, E. H. (2009). Consumer reporting of adverse drug reactions. Drug safety, 32(11), 1067-1074. https://doi.org/10.2165/11316680-000000000-00000

Ahmad, S. R. (2003). Adverse drug event monitoring at the Food and Drug Administration: your report can make a difference. Journal of general internal medicine, 18(1), 57-60. https://doi.org/10.1046/j.1525-1497.2003.20130.x 
Ayani, I., Aguirre, C., Gutierrez, G., Madariaga, A., Rodríguez - Sasiaín, J., \& Martínez - Bengoechea, M. (1999). A cost - analysis of suspected adverse drug reactions in a hospital emergency ward. Pharmacoepidemiology and drug safety, 8(7), 529-534. https://doi.org/10.1002/(SICI)1099-1557(199912)8: 7<529::AID-PDS460>3.0.CO;2-J

Bateman, D. N., Sanders, G. L. S., \& Rawlins, M. D. (1992). Attitudes to adverse drug reaction reporting in the Northern Region. British Journal of Clinical Pharmacology, 34(5), 421-426.

Belton, K. J., Lewis, S. C., Payne, S., Rawlins, M., \& Wood, S. (1995). Attitudinal survey of adverse drug reaction reporting by medical practitioners in the United Kingdom [see comments]. British journal of clinical pharmacology, 39(3), 223-226. https://doi.org/10.1111/j.1365-2125.1995.tb04440.x

Blenkinsopp, A., Wilkie, P., Wang, M., \& Routledge, P. A. (2007). Patient reporting of suspected adverse drug reactions: A review of published literature and international experience. British Journal of Clinical Pharmacology, 63(2), 148-156. https://doi.org/10.1111/j.1365-2125.2006.02746.x

Cosentino, M., Leoni, O., Banfi, F., Lecchini, S., \& Frigo, G. (1997). Attitudes to adverse drug reaction reporting by medical practitioners in a Northern Italian district. Pharmacological research, 35(2), 85. https://doi.org/10.1016/S1043-6618(02)00281-5

Desai, C. K., Iyer, G., Panchal, J., Shah, S., \& Dikshit, R. (2011). An evaluation of knowledge, attitude, and practice of adverse drug reaction reporting among prescribers at a tertiary care hospital. Perspectives in Clinical research, 2(4), 129. https://doi.org/10.4103/2229-3485.86883

Eland, Belton, Van, G., Meiners, Rawlins, \& Stricker. (1999). Attitudinal survey of voluntary reporting of adverse drug reactions. British Journal of Clinical Pharmacology, 48(4), 623-627. https://doi.org/10.1046/j.1365-2125.1999.00060.x

Fadare, J. O., Enwere, O. O., Afolabi, A. O., Chedi, B. A. Z., \& Musa, A. (2011). Knowledge, Attitude and Practice of Adverse Drug Reaction Reporting among Healthcare Workers in a Tertiary Centre in Northern Nigeria. Tropical Journal of Pharmaceutical Research, 10(3). https://doi.org/10.4314/tjpr.v10i3.4

Feely, J., Moriarty, S., \& O'Connor, P. (1990). Stimulating reporting of adverse drug reactions by using a fee. BMJ: British Medical Journal, 300(6716), 22. https://doi.org/10.1136/bmj.300.6716.22

Figueiras, A., Tato, F., Fontai-as, J., \& Gestal-Otero, J. J. (1999). Influence of physicians' attitudes on reporting adverse drug events: A case-control study. Medical care, 809-814. https://doi.org/10.1097/00005650-199908000-00010

Goldman, S. A. (1998). Limitations and strengths of spontaneous reports data. Clinical Therapeutics, 20(C), C40-C44. https://doi.org/10.1016/S0149-2918(98)80007-6

Gupta, P., \& Udupa, A. (2011). Adverse Drug Reaction Reporting and Pharmacovigilance: Knowledge, Attitudes and Perceptions amongst Resident Doctors. Journal of Pharmaceutical Sciences and Research, 3(2), 1064-1069.

Hasford, J., Goettler, M., Munter, K.-H., \& Müller-Oerlinghausen, B. (2002). Physicians' knowledge and attitudes regarding the spontaneous reporting system for adverse drug reactions. Journal of clinical epidemiology, 55(9), 945-950. https://doi.org/10.1016/S0895-4356(02)00450-X

Herdeiro, M. T., Figueiras, A., Polónia, J., \& Gestal-Otero, J. J. (2005). Physicians' attitudes and adverse drug reaction reporting: A case-control study in Portugal. Drug safety, 28(9), 825. https://doi.org/10.2165/00002018-200528090-00007

Khalili, H., Mohebbi, N., Hendoiee, N., Keshtkar, A.-A., \& Dashti-Khavidaki, S. (2012). Improvement of knowledge, attitude and perception of healthcare workers about ADR, a pre- and post-clinical pharmacists' interventional study. BMJ Open, 2(1). https://doi.org/10.1136/bmjopen-2011-000367

Launiala, A. (2009). How much can a KAP survey tell us about people's knowledge, attitudes and practices? Some observations from medical anthropology research on malaria in pregnancy in Malawi. Anthropology Matters, Retrieved from https://anthropologymatters.com/index.php/anth_matters/article/view/31

Lazarou, J., Pomeranz, B. H., \& Corey, P. N. (1998). Incidence of adverse drug reactions in hospitalized patients: a meta-analysis of prospective studies. Jama, 279(15), 1200-1205. https://doi.org/10.1001/jama.279.15.1200

Lexchin, J. (2006). Is there still a role for spontaneous reporting of adverse drug reactions? CMAJ: Canadian Medical Association journal = journal de l'Association medicale canadienne, 174(2), 191. 
http://dx.doi.org/10.1503/cmaj.050971

Li, Q., Zhang, S.-M., Chen, H.-T., Fang, S.-P., Yu, X., Liu, D., . . Zeng, F.-D. (2004). Awareness and attitudes of healthcare professionals in Wuhan, China to the reporting of adverse drug reactions. Chinese medical journal, $117(6), 856$.

Milstien, J. B., Faich, G. A., Hsu, J. P., Knapp, D. E., Baum, C., \& Dreis, M. W. (1986). Factors Affecting Physician Reporting of Adverse Drug Reactions. Retrieved from http://journals.sagepub.com/doi/abs/10.1177/009286158602000207

Muraraiah, S., Rajarathna, K., Divyasree, S., Basavalingu, D., \& Jayanthi, D. (2011). A questionnaire study to assess the knowledge, attitude and practice of Pharmacovigilance in a paediatric tertiary care centre. Journal of Chemical and Pharmaceutical Research, 3(6), 416-422.

Murphy, B., \& Frigo, L. (1993). Development, implementation, and results of a successful multidisciplinary adverse drug reaction reporting program in a university teaching hospital. Hospital pharmacy, 28(12), 1199-1204, 1240.

Oshikoya, K. A., \& Awobusuyi, J. O. (2009). Perceptions of doctors to adverse drug reaction reporting in a teaching hospital in Lagos, Nigeria. BMC Clinical Pharmacology, 9(1), 14-14. https://doi.org/10.1186/1472-6904-9-14

Palaian, S., Ibrahim, M. I., \& Mishra, P. (2011). Health professionals' knowledge, attitude and practices towards $\begin{array}{lllll}\text { pharmacovigilance } \quad \text { in } \quad \text { Nepal. } & \text { Pharmacy } 228 .\end{array}$ https://doi.org/10.4321/S1886-36552011000400008

Paveliu, M. S., Bengea-Luculescu, S., Toma, M., \& Paveliu, S. F. (2013). Perception on adverse drug reaction reporting by physicians working in southern romania. Maedica, 8(1), 17.

Pougetzago, P., Lapeyremestre, M., Bagheri, H., \& Montastruc, J. L. (1995). [pharmacovigilance seen by a selected group of general practitioners and of residents in the midi-pyrenees region]. Thérapie, 50(5), 459. Retrieved from https://www.ncbi.nlm.nih.gov/pubmed/8571286

Rajesh, R., Vidyasagar, S., \& Nandakumar, K. (2011). Highly active antiretroviral therapy induced adverse drug reactions in Indian human immunodeficiency virus positive patients. Pharmacy Practice, 9(1), 48-55. https://doi.org/10.4321/S1886-36552011000100008

Ralph Edwards, I., \& Olsson, S. (2002). WHO programme_-global monitoring. Pharmacovigilance, $167-182$.

Ramesh, M., Pandit, J., \& Parthasarathi, G. (2003). Adverse drug reactions in a South Indian hospital- their severity and cost involved. Pharmacoepidemiology and Drug Safety, 12(8), 687-692. https://doi.org/10.1002/pds.871

Rehan, H. S., Vasudev, K., \& Tripathi, C. D. (2002). Adverse drug reaction monitoring: knowledge, attitude and practices of medical students and prescribers. Retrieved from https://www.researchgate.net/profile/Harmeet_Rehan/publication/11505275_Adverse_drug_reaction_monit oring_Knowledge_attitude_and_practices_of_medical_students_and_prescribers/links/0a85e5356c3ad3370 f000000/Adverse-drug-reaction-monitoring-Knowledge-attitude-and-practices-of-medical-students-and-pre scribers.pdf

Rishi, R. K., Patel, R., \& Bhandari, A. (2012). Under reporting of ADRs by medical practitioners in India-results of pilot study. Adv Pharmacoepidem Drug Saf, 1(3), 112.

Rogers, A. S., Israel, E., Smith, C. R., Levine, D., McBean, A. M., Valente, C., \& Faich, G. (1988). Physician Knowledge, Attitudes, and Behavior Related to Reporting Adverse Drug Events. Archives of Internal Medicine, 148(7), 1596-1600. https://doi.org/10.1001/archinte.1988.00380070090021

Scott, H. D., Thacher-Renshaw, A., Rosenbaum, S. E., Waters, W. J., Green, M., Andrews, L. G., \& Faich, G. A. (1990). Physician Reporting of Adverse Drug Reactions: Results of the Rhode Island Adverse Drug Reaction Reporting Project. JAMA, 263(13), 1785-1788. https://doi.org/10.1001/jama.1990.03440130073028

Smith, C., Bennett, P., Pearce, H., Harrison, P., Reynolds, D., Aronson, J., \& Grahame - Smith, D. (1996). Adverse drug reactions in a hospital general medical unit meriting notification to the Committee on Safety of Medicines. British journal of clinical pharmacology, 42(4), 423-429. https://doi.org/10.1111/j.1365-2125.1996.tb00004.x

Tabali, M., Jeschke, E., Bockelbrink, A., Witt, C. M., Willich, S. N., Ostermann, T., \& Matthes, H. (2009). 
Educational intervention to improve physician reporting of adverse drug reactions (ADRs) in a primary care setting in complementary and alternative medicine. BMC Public Health, 9, $274-274$. https://doi.org/10.1186/1471-2458-9-274

Vallano, A., Cereza, G., Pedròs, C., Agustí, A., Danés, I., Aguilera, C., \& Arnau, J. (2005). Obstacles and solutions for spontaneous reporting of adverse drug reactions in the hospital. British journal of clinical pharmacology, 60(6), 653-658. https://doi.org/10.1111/j.1365-2125.2005.02504.x

Van Hunsel, F., Passier, A., \& Van Grootheest, K. (2009). Comparing patients' and healthcare professionals' ADR reports after media attention: the broadcast of a Dutch television programme about the benefits and risks of statins as an example. British Journal of Clinical Pharmacology, 67(5), 558-564. https://doi.org/10.1111/j.1365-2125.2009.03400.x

Waller, P. C. (2006). Making the most of spontaneous adverse drug reaction reporting. Basic \& clinical pharmacology \& toxicology, 98(3), 320-323. https://doi.org/10.1111/j.1742-7843.2006.pto_286.x

World Health Organization. (2002). Safety of medicines: a guide to detecting and reporting adverse drug reactions: why health professionals need to take action (No. WHO/EDM/QSM/2002.2). Retrieved from http://apps.who.int/iris/bitstream/handle/10665/67378/W?sequence=1

Wu, W. K., \& Pantaleo, N. (2003). Evaluation of outpatient adverse drug reactions leading to hospitalization. American journal of health-system pharmacy, 60(3), 253-259.

Wysowski, D. K., \& Swartz, L. (2005). Adverse drug event surveillance and drug withdrawals in the United States, 1969-2002: The importance of reporting suspected reactions. Archives of internal medicine, 165(12), 1363-1369. https://doi.org/10.1001/archinte.165.12.1363

\section{Copyrights}

Copyright for this article is retained by the author(s), with first publication rights granted to the journal.

This is an open-access article distributed under the terms and conditions of the Creative Commons Attribution license (http://creativecommons.org/licenses/by/4.0/). 